\title{
Estimation of contaminant transport parameters for a tropical sand in a sand tank model
}

\author{
*O. O. Ojuri; S. A. Ola \\ Department of Civil Engineering, Federal University of Technology, Akure, Ondo State, Nigeria \\ Received 17 April 2009; $\quad$ revised 10 November 2009; accepted 17 December 2009; avaiable online 1 March 2010
}

\begin{abstract}
This research describes the goals, design and implementation of a quasi natural gradient, laboratory scale, sand tank (aquifer) model experiment. The model was used to study the transport of an inorganic tracer (Chloride) in groundwater, within a tropical aquifer (porous medium) material. Three-dimensional sand tank $(1.8 \mathrm{~m} \times 0.3 \mathrm{~m} \times 0.8$ $\mathrm{m}$ ) experiments were conducted to investigate contaminant transport and natural attenuation within the sand tank. In all, 360 samples were collected during 24 sampling sessions, for the three days of the tracer experiments in the Sand Tank. The Owena sand is a poorly graded sand with $88.1 \%$ sand and $11.9 \%$ gravel. Geotechnical properties including; coefficient of uniformity $\mathrm{C}_{\mathrm{u}}=2.53$, coefficient of gradation $\mathrm{C}_{\mathrm{z}}=0.181$, hydraulic conductivity $\mathrm{K}=5.76 \times 10^{-4} \mathrm{~m} / \mathrm{s}$, bulk density $\rho=1.9 \mathrm{Mg} / \mathrm{m}^{3}$, effective porosity $\mathrm{n}_{\mathrm{e}}=0.215$ and median grain diameter $\mathrm{D}_{50}=0.55 \mathrm{~mm}$, were determined. Other relevant hydraulic and solute transport parameters, such as dispersion coefficients and dispersivities were also established for the tropical soil.
\end{abstract}

Keywords: Aquifer model; Geotechnical properties; Owena sand; Solute transport parameters; Tracer breakthrough

\section{INTRODUCTION}

The prevalence of the casual handling of petroleum hydrocarbon storage, distribution and dispensing facilities, such as underground tanks, pipelines and gasoline stations in developing countries like Nigeria necessitates this research focus. Indiscriminate sewage and industrial effluent disposal is also of grave concern. In Nigeria, 335,200 deaths occur annually from sanitation, water and hygiene related infections, signifying a $16.7 \%$ of deaths. This is indicated in the World Health Organisation (WHO), country-bycountry data on the burden of water, sanitation and hygiene related deaths globally (Victor, 2008). There is now an urgent need to scientifically harness both human and material resources especially in the emerging field of geoenvironmental engineering in order to meet the target 10 (Halve, by 2015, the proportion of people without sustainable access to safe drinking water and basic sanitation) of the pertinent millennium development goal (goal 7 - ensure environmental sustainability). The aim of this research is to fabricate a $3-\mathrm{D}$ intermediate scale sand tank model, characterize the porous medium material (Owena Sand) and the flow characteristics of the sand tank

* * Corresponding Author Email: ojurip@yahoo.com

Tel.: +234 80343 39391; Fax: +23434230450 model. Relevant solute transport parameters for the tropical porous media soil would also be evaluated (Das et al., 2008). The scientific hypothesis is that both the seepage velocity and the porous media hydrodynamic parameters; dispersion coefficient and dispersivity, control the spread of contaminants in ground water flow system and this is dominant in the central longitudinal axis of the contaminant source, in a homogeneous porous medium (Adams et al., 2008). Increase in the dispersion of the tracer would lead to its attenuation in the porous media. Several researchers, in the area of groundwater/subsurface contaminant engineering, have studied contaminant transport and transformation in 1-D laboratory soil column (Jebellie et al., 2004; Adams and GuzmanOsorio, 2008; Mirbagheri and Hashemi Monfared, 2009). Sand tank model is a 3-D physical aquifer model and ever since, early 1980s, it has been widely employed in several fields of study in the laboratory to observe groundwater flow and solute transport (Wildenschild et al., 1994; / HWOG\&KrysikopouloV[1998; Pignatello, 1989; Olaf et al., 2003; Ursino and Gimmi, 2004; Kim et al., 2005). A three-dimensional physical aquifer model was used to study the dissolution of a dense nonaqueous phase liquid (DNAPL) pool. The model aquifer 
comprised a packing of homogeneous, medium-sized sand and conveyed steady, unidirectional flow, (Dela Barre et al., 2002).

Jung et al., 2006 also investigated injection of edible oils into the subsurface. Injection of edible oil into a laboratory sand tank model can provide an effective, low-cost alternative for simulating anaerobic bioremediation processes. However, concerns have been raised about the effects of oil buoyancy and variations in aquifer permeability on the final distribution of oil in the subsurface. Three-dimensional (3D) sandbox experiments $(1.2 \mathrm{~m} \times 0.98 \mathrm{~m} \times 0.98 \mathrm{~m})$ were conducted to study the distribution of edible oil emulsions under homogeneous and heterogeneous conditions. A fine emulsion was first injected followed by chase water to distribute the emulsion throughout the sandbox. This approach was very effective, resulting in a reasonably uniform volatile solids distribution in the top, middle and bottom layers.

Laboratory and numerical modeling investigation were completed to study the unconfined groundwater flow and transport processes near a seepage-face boundary (Simpson et al., 2003). The laboratory observations were made in a radial sand tank and included measurements of the height of the seepageface, flow velocity near the seepage-face, travel time distribution of multiple traces slugs, and streamlines. The results imply that vertically average flow models that employ dupuit approximations might introduce error in the analysis of localized solute transport near a seepage-face boundary.

Groundwater moves from areas of higher elevation or higher pressure/hydraulic head (recharge areas) to areas of lower elevation or pressure/hydraulic head. In 1856, Henri Darcy first concluded that velocity of flow through a porous media was directly proportional to the gradient of piezometric head (hydraulic gradient) (Walton, 1991). The most important processes play a role in the transport of solutes in groundwater (Freeze and Cherry, 1979; Domenico and Schwartz, 1990; Plamer, 1992) are; advection: the processes whereby the solute is carried by the average groundwater velocity through the porous medium and mechanical dispersion; the processes that cause variations from the average transport pathway on account of the tortuous structure of the pore space of natural porous media.

Dispersivities are scale dependent with respect to numerical model grids and depend on how explicitly field velocity distribution and actual geometry of aquifer heterogeneity are simulated in numerical models (Freyberg, 1986; Sudicky, 1986; Held and Celia, 2001). Predictions of future plume migration may require selection of dispersivity values significantly different from calibrated model values. In profile, contaminant migration tends to be concentrated in the more permeable zones of uniformly porous aquifers causing fingering and irregularity in plumes (MacKay and Cherry 1989; Mackay et al., 1991). However, diffusion from permeable zones into adjacent less permeable zones tends to create more regular plumes as concentrations are reduced in zones of dispersion and advection and concentrations are increased in the zones of lesser flow (Lee and Chrysikopoulos, 1998; Kleineidam et al., 1999; Kasteel et al., 2000; Wang et al., 2009). In general, dispersivity is directionally dependent on aquifer vertical, and horizontal hydraulic conductivity variations, and increases with the degree of aquifer heterogeneity and anisotropy - directional dependent. The 3-D intermediate scale sand tank (aquifer) model presented in this research was designed, fabricated, assembled and evaluated in 2007 at the geotechnical engineering laboratory, department of Civil Engineering, Federal University of Technology, Akure, Ondo State, Nigeria.

\section{MATERIALS AND METHODS}

Laboratory sand tank (aquifer) model experimental set-up

Sand tank model as used in this research work is a 3dimensional physical model apparatus consisting of transparent glass and plexiglass material - which enables an observer to clearly monitor the simulated groundwater flow and solute transport in the laboratory. The model attempts to simulate how groundwater is contaminated and the rate at which the contaminant spreads in the groundwater both longitudinally and transversely. The laboratory sand tank model was fabricated with $1 \mathrm{~cm}$ thick glass sheets. The size of the tank is $1.8 \mathrm{~m} \times 0.3 \mathrm{~m} \times 0.8 \mathrm{~m}$. The sand tank model was sub-divided into three chambers using acrylic material (Plexi-glass), but perforated to allow water to flow through it. On the discharge side of the sand tank model, five $18.75 \mathrm{~mm}$ diameter openings were drilled to create differential hydraulic gradient; with equal head difference of $0.05 \mathrm{~m}$ for 4 openings. While the $5^{\text {th }}$ opening was drilled $0.025 \mathrm{~m}$ above the base (This is for draining the tank). One $18.75 \mathrm{~mm}$ diameter opening was drilled on the inlet side at $0.73 \mathrm{~m}$ height of the sand tank model (Fig. 1). 


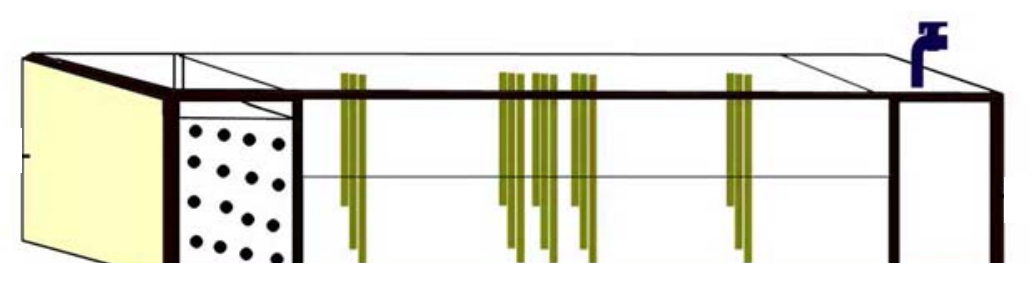

a) Arragement of the piped sampling points

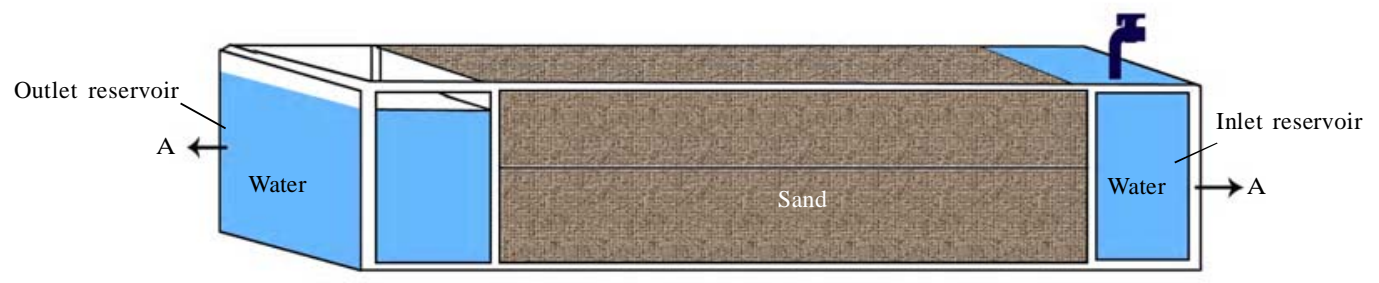

b) Nests of multilevel pipes emplaced in the sand champer

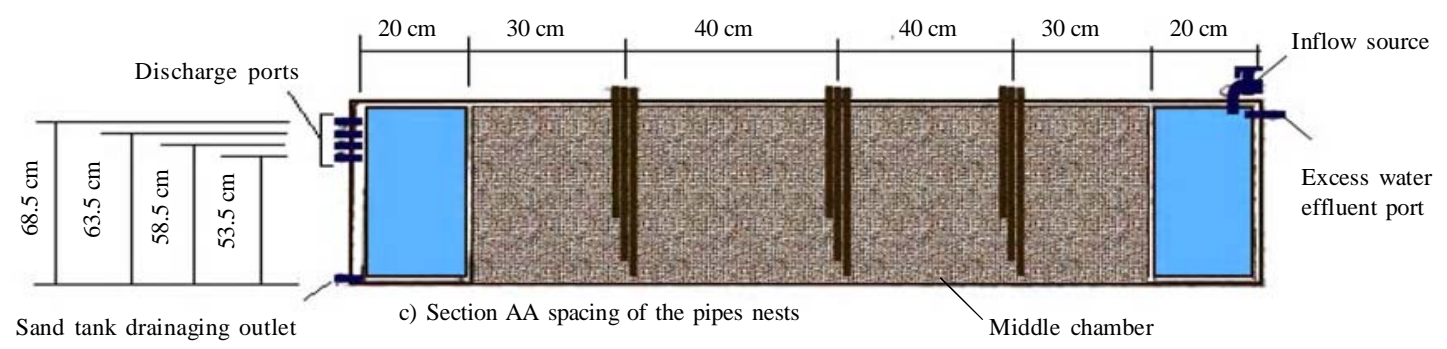

Fig. 1: Isometric and section view of the laboratory sand tank, showing the arrangement of the multilevel pipes

In order to counter the stresses that will arise as a result of the retained material in the sand tank model, angle iron sizes of the following dimensions: $0.05 \mathrm{~m} \times$ $0.05 \mathrm{~m} \times 0.003 \mathrm{~m}$ thick and $0.025 \mathrm{~m} \times 0.025 \mathrm{~m} \times 0.003 \mathrm{~m}$ thick, respectively were utilized to fabricate a reinforcing framework externally around the glassplexiglass composite material tank. It served a dual purpose of also helping to elevate the sand tank model to position for easy monitoring; that is $0.9 \mathrm{~m}$ above the ground. A 500-gallon plastic water container was used as a source of water to the sand tank model. Water was harvested into the 500 gallon storage from the elevated roof storage tank by means of a tee connected to the discharge pipe, from the roof tank into the 500 gallon storage water source. The effective invert level of the sand tank model when it is dry, without water, is $0.95 \mathrm{~m}$ and when it is full with the side opening on the inlet side open, the effective level of water is equal to 1.68 $\mathrm{m},(0.95+0.73) \mathrm{m}$. The inlet level of the source water tank is $1.80 \mathrm{~m}$. When the source water tank is full, the level of water in it will be $2.7 \mathrm{~m}$. Therefore, the head difference between the source water when it is full and the inlet source water in the sand tank model when it is also full at $1.68 \mathrm{~m}$ marks will be $1.02 \mathrm{~m}$. An elevated steel, $0.75 \mathrm{~m} \times 0.075 \times 0.005 \mathrm{~m}$ thick, platform with battered legs and braced internally, was used to hold the elevated source water tank in position. As was earlier stated, the sand tank model was sub-divided into 3 chambers; viz. the inlet, middle and outlet chambers. The first serves as the inlet reservoir (for maintaining constant head), with the perforated separator serving as a pathway for the water to flow into the middle chamber where the Owena River sand is retained. The river sand was wet packed in the middle chamber's to minimize consolidation and air entrapment. This process was gradually done, to allow the stresses resulting from the impact to be minimized. The middle chamber's was finally filled to the brim with the river sand in lifts. Also, the sampling pipes, which are 5 nests of multilevel pipes, were also positioned, with first and the fifth one positioned $30 \mathrm{~cm}$ away from the inlet and outlet perforated separator, respectively. While the central 3 
nests were arranged $70 \mathrm{~cm}$ away from the inlet and outlet perforated separators transversely across (Fig. 1)

Each multilevel nest was made up of three $12.5 \mathrm{~mm}$ diameter pipe cuts of the following length $42 \mathrm{~cm}, 62 \mathrm{~cm}$ and $82 \mathrm{~cm}$ with a plastic stopper at the lower end and a screen cut close to the plastic stopper with a mesh wrapped round it to prevent fine sand migrating into the 12 number sampling ports. An adhesive tape was used to bind the three $12.5 \mathrm{~mm}$ diameter pipes together to form the multilevel nest. The screen allows water to flow into the $12.5 \mathrm{~mm}$ diameter pipe, until it attains the piezometric head. The screen of the multilevel pipes enables the depth discrete sampling of the fluid contained in the aquifer model. After sand packing the middle chambers of the sand tank model with the characterized river sand material (Owena River sand), water was allowed to flow freely through the sand medium from the inlet chamber, which was being feed continuously from the temporary storage elevated tank.

Table 1: Calculations of grading parameters from the particle size distribution curves

\begin{tabular}{llll}
\hline Sample A & Sample B & Sample C & Average \\
\hline $\mathrm{D}_{10}=0.24$ & $\mathrm{D}_{10}=0.23$ & $\mathrm{D}_{10}=0.24$ & $\mathrm{D}_{10}=0.24$ \\
$\mathrm{D}_{30}=0.44$ & $\mathrm{D}_{30}=0.40$ & $\mathrm{D}_{30}=0.45$ & $\mathrm{D}_{30}=0.43$ \\
$\mathrm{D}_{50}=0.54$ & $\mathrm{D}_{50}=0.55$ & $\mathrm{D}_{50}=0.56$ & $\mathrm{D}_{50}=0.55$ \\
$\mathrm{D}_{60}=0.80$ & $\mathrm{D}_{60}=0.70$ & $\mathrm{D}_{60}=0.70$ & $\mathrm{D}_{60}=0.73$ \\
Uniformity coefficient $\left(\mathrm{C}_{\mathrm{u}}\right)$ & Coefficient of gradation $\left(\mathrm{C}_{\mathrm{z}}\right)$ \\
{$\left[C_{u}=\frac{D_{60}}{D_{10}}=\frac{0.73}{0.24}=3.04\right]$} & $C_{2}=\frac{D_{30}^{2}}{D_{60} \times D_{10}}=\frac{0.43^{2}}{0.73+0.24}=0.191$ \\
\hline
\end{tabular}

The preferred discharge port was opened, while keeping the other three ports closely locked. Water was allowed to flow freely through it for about $1 \mathrm{~h}$, to attain a steady flow. Thereafter, the flow rate was measured. This process was repeated for all the other 3 ports and readings of flow rates recorded.

Characterization of the porous media and flow characteristics

A measure of the coastal river sand (700 g) was weighed and used in the sieve analysis. After which the various constituents material retained on each sieves were weighed and recorded. The test was conducted in accordance with the British Standards, BS 1377 (1990) (Code of Practice). This exercise was repeated for 3 separate samples taken at random from the river sand. The Owena River sand material is relatively homogeneous medium-to-fine-grained sand. Clay size fractions are almost absent (Fig. 2). Calculations of the effective size $\left(D_{10}\right)$, median grain diameter $\left(\mathrm{D}_{50}\right)$ uniformity coefficient $\left(\mathrm{C}_{\mathrm{u}}\right)$ and the coefficient of gradation $\left(\mathrm{C}_{\mathrm{z}}\right)$ from the graph are presented in Table 2 . The river sand is poorly graded sand (SP).

The results of the characterization of the geotechnical, hydraulic and geochemical properties of the Owena sand from independent laboratory analyses are presented in Table 2a. The groundwater flow characteristics of the alluvial sand (Owena sand) material are in Tables $2 b$.

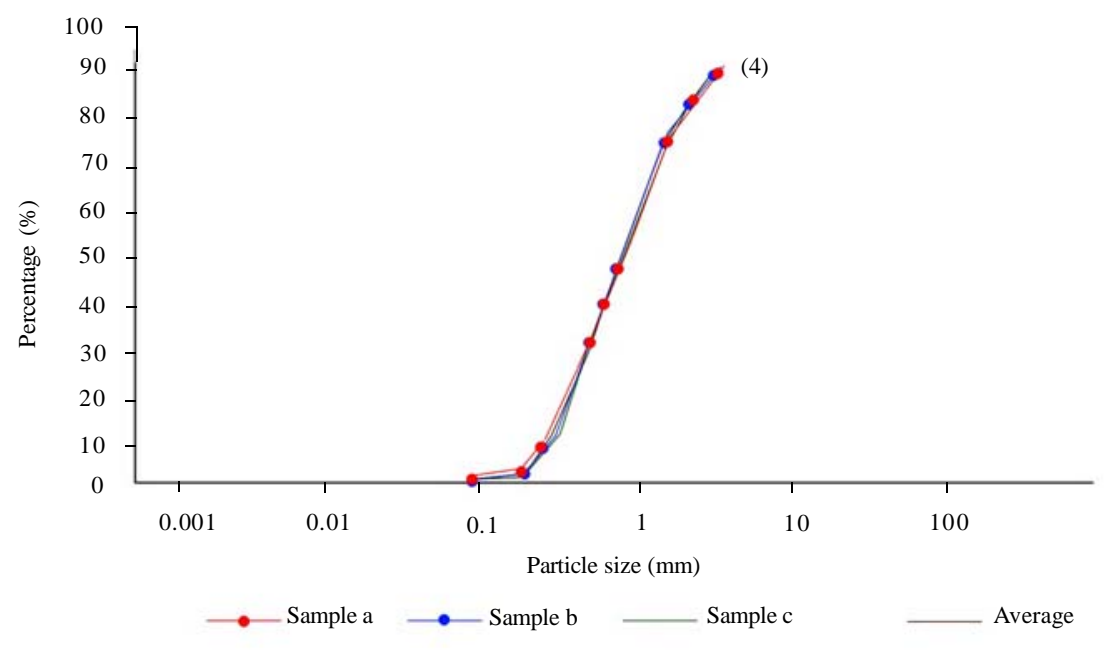

Fig. 2: Combined particle size distribution curve for samples A, B, C 
Tracer experiment: experimental procedures

An injection system was designed to approach the ideal goal of creating essentially instantaneous and with minimal disturbance of the natural flow field. Three injection wells arranged in Fig. 1 were each slotted and screened within the saturated zone, over the vertical interval $0.42-0.82 \mathrm{~m}$ below the aquifer model surface. The injection system was designed to provide to each of the injection wells an equal (20 $\mathrm{mL}$ ) and uniform flow of a solution of uniform composition (12 g/L) [28.1 mS/cm]. $12.0 \mathrm{~g}$ of sodium chloride dissolved in $1000 \mathrm{~mL}$ of water was injected into three upgradient injection wells on July 17, 2007. Injection period was $5 \mathrm{~min}$. The average concentration was $12000 \mathrm{mg} / \mathrm{L}$ with aqueous diffusion coefficient was $2.03 \times 10^{-9} \mathrm{~m}^{2} / \mathrm{s}$ (Cussler, 1984). Observation wells (4 mini wells) were located $40 \mathrm{~cm}$ and $80 \mathrm{~cm}$ away from the injection wells, in the middle chamber of the sand tank model. The chloride conductivity of at the observation wells were measured using a portable Horiba U-10 water quality checker. The measurement interval varied between 1 and $10 \mathrm{~h}$. A $20 \mathrm{~mL}$ syringe and $5 \mathrm{~mm}$ diameter Teflon siphon tube was used for

Table 2a: Estimates of Owena sand geotechnical, hydraulic and geochemical properties

\begin{tabular}{llr}
\hline & Property & Estimates \\
\hline 1 & Bulk density $\left(\mathrm{mg} / \mathrm{m}^{3}\right)$ & 1.9 \\
2 & Porosity (\%) & 32 \\
3 & WHC (\%) & 30.2 \\
4 & Hydraulic conductivity (m/s) & $5.76 \times 10^{-4}$ \\
5 & pH in Water & 7.52 \\
6 & pH in KCL & 6.52 \\
7 & Org. C [foc & 0.0008 \\
8 & Total N (\%) & 0.03 \\
9 & Av. P (ppm) & 6.9 \\
10 & Exc. Ca (me/100g) & 0.58 \\
11 & Exc. Mg (me/100g) & 0.54 \\
12 & Exc. Na (me/100g) & 0.12 \\
13 & Exc. K (me/100g) & 0.12 \\
14 & CEC (me/100g) & 1.36 \\
15 & B. Sat (\%) & 87.18 \\
\hline
\end{tabular}

Note: WHC: Water holding capacity, CEC: Cation exchange capacity, Exc.: Exchangable, B. Sat: Base saturation, ME: Milli equivalent, foc: fraction of organic carbon collection of the samples into $50 \mathrm{~mL}$ plastic bottles. The tester, syringe and the siphon tube were rinsed with distilled water before and after each measurement. After injection the plume of solute moved under the action of the quasi natural gradient of the sand tank and the elevated water reservoir as expected (Hassan et al., 2008). Plume movement was monitored using a network of multilevel point samplers. The spatial and temporal distribution of data collected for the tracer is summarized in Table 3 . In all 360 samples were collected during 24 sampling sessions, for the three days of the tracer experiments in the Sand Tank. Elapsed travel time was $34 \mathrm{~h}$, with a maximum travel distance of $0.8 \mathrm{~m}$.

\section{RESULTS AND DISCUSSION}

From the characterization of the geotechnical, hydraulic and geochemical properties of the chosen experimental sand (Owena sand) presented in Fig. 2, Table 1 and Table 2a, the sand can be described as coarse, medium to fine sand. Based on the gradation coefficients in Table 1, the Owena sand is a poorly graded soil. This was taken into consideration in the packing of the sand in the physical aquifer model. The sand tank was packed under a $5 \mathrm{~cm}$ water column and the wet sand was compacted, to avoid grain size separation as the sand settled through the water column. The water level was raised after packing every $5 \mathrm{~cm}$. A well graded soil will have a uniformity coefficient greater than about 4 for gravels and 6 for sands and a coefficient of gradation between 1 and 3 for gravels and sands (Das, 1990). The bulk density obtained for the experimental sand $\left(1.9 \mathrm{Mg} / \mathrm{m}^{3}\right)$ corresponds to that of dense fine/coarse sand (Ola, 1983). The hydraulic conductivity from Table 3a also agrees with that of fine to coarse sand (Das, 1990). A low total cation exchange capacity (CEC) of $1.36 \mathrm{me} / 100 \mathrm{~g}$ for the Owena sand reveals the near absence of clays in the alluvial sand (Torres et al., 2007). Clays of low plasticity have CEC values between 3 and 8 , while highly plastic clays

Table 2b: Sand tank flow characteristics

\begin{tabular}{lcccccc}
\hline S/N & Head outlet $(\mathrm{cm})$ & Head inlet $(\mathrm{cm})$ & $\begin{array}{c}\text { Head difference } \\
(\mathrm{dh}) \mathrm{cm}\end{array}$ & Gradient dh/dl & $\begin{array}{c}\text { Outflow rate } \\
(\mathrm{ml} / \mathrm{min}) \mathrm{ml} / \mathrm{min}\end{array}$ & \begin{tabular}{c} 
Discharge ports \\
\hline 1
\end{tabular} \\
\hline 68.5 & 73 & 4.5 & 0.0321 & 58 & 160 \\
2 & 63.5 & 73 & 9.5 & 0.0679 & $1^{\text {st }}$ Port & $2^{\text {nd }}$ Port \\
3 & 58.5 & 73 & 14.5 & 0.1036 & 280 \\
4 & 53.5 & 73 & 19.5 & 0.1393 & $3^{\text {rd }}$ Port & 405 \\
\hline
\end{tabular}


O. O. Ojuri; S. A. Ola

Table 3: Spatial and temporal distribution of chloride conductivity for the tracer experiment ( $1^{\text {st. }}$ port)

\begin{tabular}{|c|c|c|c|c|c|c|c|}
\hline & & $\begin{array}{l}\text { Conductivity } \\
(\mathrm{mS} / \mathrm{cm})\end{array}$ & $\begin{array}{l}\text { Conductivity } \\
(\mathrm{mS} / \mathrm{cm})\end{array}$ & $\begin{array}{l}\text { Conductivity } \\
(\mathrm{mS} / \mathrm{cm})\end{array}$ & $\begin{array}{l}\text { Conductivity } \\
(\mathrm{mS} / \mathrm{cm})\end{array}$ & $\begin{array}{l}\text { Conductivity } \\
(\mathrm{mS} / \mathrm{cm})\end{array}$ & \\
\hline $\begin{array}{l}\text { Sampling } \\
\text { point }\end{array}$ & & A & B & $\mathrm{C}$ & D & $\mathrm{E}$ & $\begin{array}{l}\text { Time after } \\
\text { injection (h) }\end{array}$ \\
\hline \multirow[t]{3}{*}{ Sample 1} & Top & 0.286 & 0.285 & 0.283 & 0.285 & 0.286 & \\
\hline & Middle & 0.283 & 0.286 & 0.286 & 0.283 & 0.284 & \\
\hline & Bottom & 0.286 & 0.284 & 0.282 & 0.284 & 0.286 & \\
\hline \multirow[t]{3}{*}{ Sample 2} & Top & 26 & 0.58 & 0.295 & 0.295 & 0.289 & \\
\hline & Middle & 26 & 0.56 & 0.29 & 0.29 & 0.289 & 1 \\
\hline & Bottom & 26 & 0.56 & 0.29 & 0.29 & 0.289 & \\
\hline \multirow[t]{3}{*}{ Sample 3} & Top & 12 & 0.732 & 0.422 & 0.423 & 0.328 & 2 \\
\hline & Middle & 12 & 0.72 & 0.416 & 0.417 & 0.324 & \\
\hline & Bottom & 12 & 0.721 & 0.413 & 0.415 & 0.322 & \\
\hline \multirow[t]{3}{*}{ Sample 4} & Top & 4.1 & 1.523 & 0.518 & 0.518 & 0.467 & 4 \\
\hline & Middle & 4.1 & 1.521 & 0.515 & 0.517 & 0.468 & \\
\hline & Bottom & 4.1 & 1.516 & 0.505 & 0.502 & 0.468 & \\
\hline \multirow[t]{3}{*}{ Sample 5} & Top & 3.407 & 3.142 & 1.138 & 1.137 & 0.833 & 6 \\
\hline & Middle & 3.41 & 3.15 & 1.138 & 1.136 & 0.834 & \\
\hline & Bottom & 3.411 & 3.105 & 1.138 & 1.132 & 0.837 & \\
\hline \multirow[t]{3}{*}{ Sample 6} & Top & 2.331 & 3.8 & 1.407 & 1.4 & 1.32 & 8 \\
\hline & Middle & 2.342 & 3.808 & 1.407 & 1.402 & 1.32 & \\
\hline & Bottom & 2.345 & 3.821 & 1.412 & 1.413 & 1.325 & \\
\hline \multirow[t]{3}{*}{ Sample 7} & Top & 1.337 & 3.202 & 1.1 & 1.104 & 1.522 & 10 \\
\hline & Middle & 1.346 & 3.206 & 1.102 & 1.108 & 1.523 & \\
\hline & Bottom & 1.348 & 3.215 & 1.11 & 1.114 & 1.528 & \\
\hline \multirow[t]{3}{*}{ Sample 8} & Top & 0.721 & 0.84 & 0.518 & 0.515 & 1.506 & 20 \\
\hline & Middle & 0.746 & 0.85 & 0.52 & 0.518 & 1.508 & \\
\hline & Bottom & 0.759 & 0.86 & 0.57 & 0.521 & 1.512 & \\
\hline \multirow[t]{3}{*}{ Sample 9} & Тор & 0.61 & 0.675 & 0.424 & 0.425 & 1.235 & 22 \\
\hline & Middle & 0.61 & 0.68 & 0.421 & 0.418 & 1.236 & \\
\hline & Bottom & 0.62 & 0.68 & 0.434 & 0.438 & 1.236 & \\
\hline \multirow[t]{3}{*}{ Sample 10} & Top & 0.484 & 0.522 & 0.306 & 0.305 & 1.043 & 24 \\
\hline & Middle & 0.482 & 0.532 & 0.308 & 0.31 & 1.046 & \\
\hline & Bottom & 0.485 & 0.528 & 0.314 & 0.315 & 1.048 & \\
\hline \multirow[t]{3}{*}{ Sample 11} & Top & 0.412 & 0.463 & 0.285 & 0.283 & 0.901 & 26 \\
\hline & Middle & 0.408 & 0.472 & 0.289 & 0.29 & 0.902 & \\
\hline & Bottom & 0.417 & 0.472 & 0.296 & 0.299 & 0.905 & \\
\hline \multirow[t]{3}{*}{ Sample 12} & Tор & 0.358 & 0.381 & 0.254 & 0.253 & 0.748 & 28 \\
\hline & Middle & 0.362 & 0.383 & 0.256 & 0.258 & 0.751 & \\
\hline & Bottom & 0.371 & 0.385 & 0.261 & 0.26 & 0.753 & \\
\hline \multirow[t]{3}{*}{ Sample 13} & Top & 0.31 & 0.346 & 0.272 & 0.269 & 0.556 & 30 \\
\hline & Middle & 0.309 & 0.348 & 0.274 & 0.276 & 0.558 & \\
\hline & Bottom & 0.317 & 0.348 & 0.278 & 0.281 & 0.567 & \\
\hline \multirow[t]{2}{*}{ Sample 14} & Top & 0.296 & 0.286 & 0.286 & 0.285 & 0.391 & 34 \\
\hline & Middle & 0.294 & 0.286 & 0.286 & 0.284 & 0.398 & \\
\hline
\end{tabular}

have CEC values of about 80 (Ranjan and Rao, 2000; Zhang et al., 2008). Representative values of fraction of organic carbon $\left(f_{o c}\right)$ for sands and silts are within the range 0.0005 to 0.007 (Wiedemeier et al., 1999). A low fraction of organic carbon $\left(f_{o c}\right)$ value of 0.0008 suggests low organic carbon content and hence cleanliness of the experimental sand. The monitoring system consisted of a network of multilevel sampling devices (Fig. 1a) (Top). Fig. 1b (middle) shows the sampling network emplaced in the sand chamber of the laboratory aquifer model. Fig. 1c (bottom) depicts the spacing and vertical distribution of the sampling points along the cross-section AA indicated in Fig. 1b (middle). The horizontal spacing of the multilevel wells varied from $40 \mathrm{~cm}$ to $80 \mathrm{~cm}$, while the vertical spacing of the sampling points was $0.20 \mathrm{~m}$. The multilevel samplers were constructed with PVC pipes (12.5 mm diameter). Plotting the breakthrough curves and examining the statistical moments of the tracer breakthrough curves, was done throughout the duration of tracer passage.

\section{Observation for the multilevel sampling points}

The tracer breakthrough curves (TBCs) for the total 


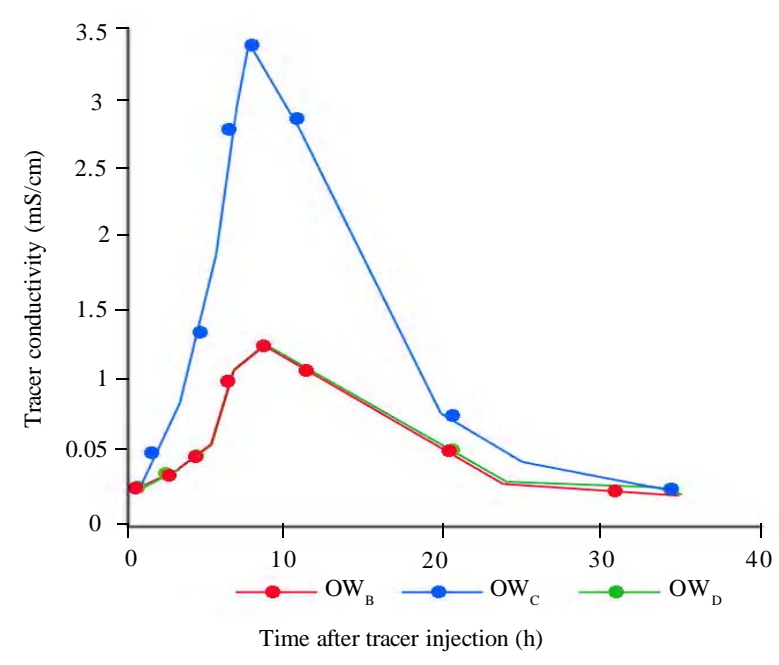

Fig. 3a: TBC for observation wells $\mathrm{OW}_{\mathrm{B}}, \mathrm{OW}_{\mathrm{C}}, \mathrm{OW}_{\mathrm{D}}$ (Port 1)

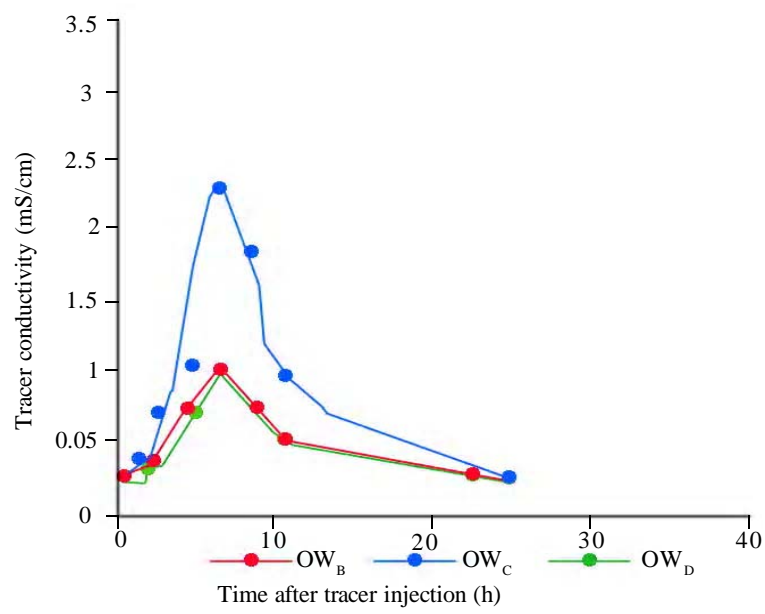

Fig. 3c: TBC for observation wells $\mathrm{OW}_{\mathrm{B}}, \mathrm{OW}_{\mathrm{C}}, \mathrm{OW}_{\mathrm{D}}$ (Port 2)

Table 4: Results from statistical moment analysis of TBC (Outflow port 1)

\begin{tabular}{cccc}
\hline $\begin{array}{l}\text { Mean travel } \\
\text { time }(\mathrm{h})\end{array}$ & $\begin{array}{c}\text { Average } \\
\text { velocity }(\mathrm{m} / \mathrm{s})\end{array}$ & $\begin{array}{c}\text { Dispersivity } \\
(\mathrm{cm})\end{array}$ & $\begin{array}{c}\text { Dispersion } \\
\text { coefficient }\left(\mathrm{m}^{2} / \mathrm{s}\right)\end{array}$ \\
\hline 4.29 & $2.59 \times 10^{-5}$ & 0.06 & $1.60 \times 10^{-6}$ \\
\hline
\end{tabular}

of 24 sampling sessions for the two different discharge rates [58 $\mathrm{mL} / \mathrm{min}$ and $160 \mathrm{~mL} / \mathrm{min}$ ] used are summarized in Fig. 3a-d.

There has been no significant difference in the TBC for The Top, Middle and Bottom positions for each of the four locations B,C,D,E. The tracer injection has also been over the entire length of the injection well A. This confirms the homogeneity of the porous media material. However, superimposition of the TBCs for the different

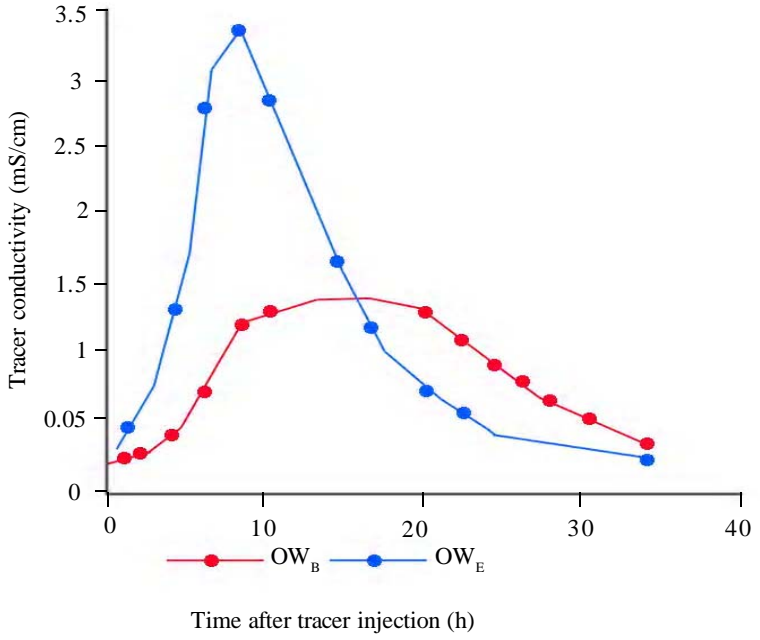

Fig. 3b: TBC for observation wells $\mathrm{OW}_{\mathrm{B}}$ and $\mathrm{OW}_{\mathrm{E}}$ (Port 1)

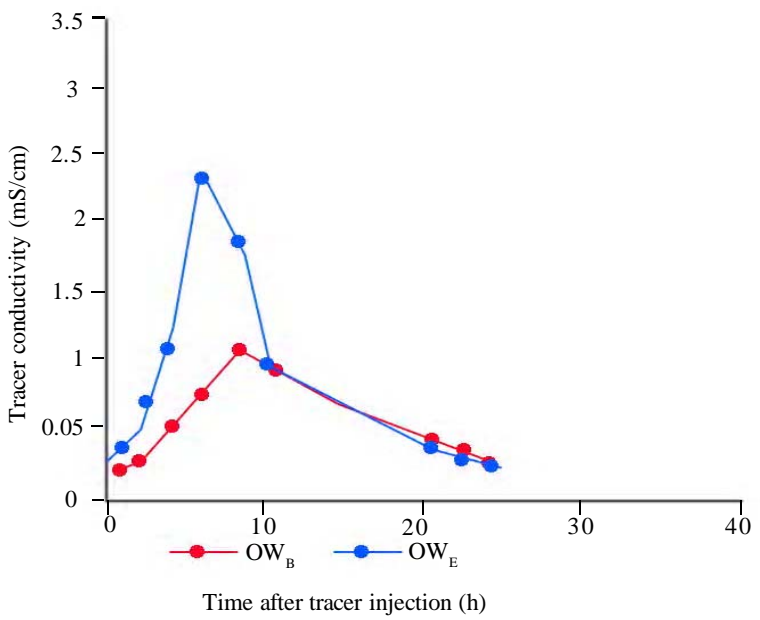

Fig. 3d: TBC for observation wells $\mathrm{OW}_{\mathrm{B}}$ and $\mathrm{OW}_{\mathrm{E}}$ (Port 2)

Table 5: Results from statistical moment analysis of TBC (Outflow port 2)

\begin{tabular}{|c|c|c|c|}
\hline $\begin{array}{c}\text { Mean Travel } \\
\text { time (h) }\end{array}$ & $\begin{array}{l}\text { Average velocity } \\
(\mathrm{m} / \mathrm{s})\end{array}$ & $\begin{array}{l}\text { Dispersivity } \\
\text { (cm) }\end{array}$ & $\begin{array}{c}\text { Dispersion } \\
\text { coefficient }\left(\mathrm{m}^{2} / \mathrm{s}\right)\end{array}$ \\
\hline 2.62 & $4.24 \times 10^{-5}$ & 0.1638 & $6.9 \times 10^{-6}$ \\
\hline
\end{tabular}

locations B, C, D, E, Fig. 3a-d, reveals that the centre of mass of the chloride plume is on the central axis along the length of the sand tank, indicated by location B. TBCs for locations $C$ and D which are $12 \mathrm{~cm}$ each away from the central axis of the tank, show a marked reduced area and hence solute mass in solution. This also indicates that the longitudinal dispersion is dominant as expected, since this is the direction of flow. For observation wells B and E, Fig. 3b, TBC for location E 
which is $40 \mathrm{~cm}$ down stream of location $\mathrm{B}$, the peak is remarkably reduced as a result of plume dilution from the flow of groundwater and the distance from the source. Increased flow of the groundwater (discharge port 2 [160 mL/min]), Fig. 3c and d, has brought about a reduction in the mass of solute in the sand tank system, due to the flushing of the tracer with the increased flow of groundwater.

\section{Statistical temporal moments of tracer breakthrough curve}

The first arrival of the chloride tracer was detected at the first observation well $\left(\mathrm{OW}_{\mathrm{BM}}\right), 1 \mathrm{~h}$ after tracer injection (Fig. 3a $\left.\left[\mathrm{OW}_{\mathrm{B}}\right]\right)$. $8 \mathrm{~h}$ after tracer injection, the chloride conductivity reached its maximum of $3.8 \mathrm{mS} / \mathrm{cm}$. After $34 \mathrm{~h}$, the conductivity had returned to the background value. The sand tank discharge rate (Port 1) stayed at $58 \mathrm{~mL} / \mathrm{min}$ during this time period. The following sections provide a quantitative assessment of a number of aspects of the preceding qualitative description of plume movement using statistical temporal moment estimates. Statistical moments of tracer breakthrough curves, was used to provide quantitative measures of various solute transport parameters, such as the velocity, dispersion coefficient and dispersivity for the porous media (Freyberg, 1986). This method of statistical moments entails finding the area under the graph of the derivative of concentration with respect to time versus time ( $\mathrm{dC} /$ dt vs. t), i.e. the zeroth moment and then obtaining the first and second moments about the mean (Cirpka and Kitanidis, 2000). Evaluation of the tracer breakthrough curve with the method of moments, yielded a mean tracer transit time of $4.29 \mathrm{~h}$. The corresponding mean tracer velocity, as well as the resulting dispersion coefficient and dispersivity are given in Table 4.

The sand tank discharge rate (Port 1 ):

$\mathrm{q}=58 \mathrm{~mL} / \mathrm{min}=9.66 \times 10^{-7} \mathrm{~m}^{3} / \mathrm{s}$

Cross-sectional area of Sand Tank (Middle chamber):

$\mathrm{A}=0.234 \mathrm{~m}^{2}$

Discharge velocity:

$v=\frac{q}{A}=4.13 \times 10^{-6} \mathrm{~m} / \mathrm{s}$

Seepage velocity:

$v_{s}=\frac{v}{n}=\frac{4.13 \times 10^{-6}}{0.32}=1.29 \times 10^{-5} \mathrm{~m} / \mathrm{s}$

Where;

$n=$ porosity
The average seepage velocity obtained from tracer breakthrough curve (Table 4) is consistent with the measured flow rate across the sand tank.

Statistical moments of tracer breakthrough curve for the second discharge rate $(160 \mathrm{~mL} / \mathrm{min})$ through the porous media model

The first arrival of the chloride tracer was detected at the first observation well $\left(\mathrm{OW}_{\mathrm{BM}}\right), 1 \mathrm{~h}$ after tracer injection (Fig. $3 \mathrm{~b}\left[\mathrm{OW}_{\mathrm{B}}\right]$ ). $6 \mathrm{~h}$ after tracer injection, the chloride conductivity reached its maximum of $2.62 \mathrm{mS} /$ $\mathrm{cm}$. After $24 \mathrm{~h}$, the conductivity had returned to the background value. The sand tank discharge rate (Port 2) stayed at $160 \mathrm{~mL} / \mathrm{min}$ during this time period.

Evaluation of the tracer breakthrough curve with the method of moments, yielded a mean tracer transit time of $2.62 \mathrm{~h}$. The corresponding mean tracer velocity as well as the resulting dispersion coefficient and dispersivity are given in Table 5.

The sand tank discharge rate (Port 1):

$\mathrm{q}=160 \mathrm{~mL} / \mathrm{min}=2.66 \times 10^{-6} \mathrm{~m}^{3} / \mathrm{s}$

Cross-sectional area of Sand Tank (Middle chamber):

$\mathrm{A}=0.234 \mathrm{~m}^{2}$

Discharge velocity:

$v=\frac{q}{A}=1.14 \times 10^{-5} \mathrm{~m} / \mathrm{s}$

Seepage velocity:

$v_{s}=\frac{v}{n}=\frac{1.14 \times 10^{-6}}{0.32}=3.55 \times 10^{-5} \mathrm{~m} / \mathrm{s}$

The seepage velocity from the sand tank model flow characteristics (Eq. 4) agrees with the average seepage velocity, computed by the statistical moment analysis of tracer breakthrough curve (Table 5). The two are within the same order of magnitude.

The dispersion coefficients and dispersivity obtained from these experiments (Table 4 and 5), are consistent with the porous media hydrodynamic parameters obtained for sandy aquifer materials with a similar plume migration distance (Leland and Hillel, 1981; Meyer et al., 1981; Iversen et al., 2008)

\section{CONCLUSION}

Laboratory aquifer model was designed, fabricated, assembled and evaluated. Steady state flow was achieved under the quasi-natural gradient condition. Physical, hydraulic and solute transport parameters were established for the tropical southwestern Nigerian 
Owena sand. This research work established contaminant transport parameters: $\mathrm{K}=5.76 \times 10^{-4} \mathrm{~m} / \mathrm{s}$, bulk density $\rho=1.9 \mathrm{Mg} / \mathrm{m}^{3}$, effective porosity $\mathrm{n}_{\mathrm{e}}=0.215$.The hydraulic gradients for the sand tank model, varies from $0.0321-0.1393$, discharge rates $(\mathrm{Q})$ from $58.0-405.0 \mathrm{~mL} / \mathrm{min}$. The analysis used was the method of statistical temporal moments of the tracer breakthrough curves, to obtain estimates for the flow velocity, dispersivity and dispersion coefficient, respectively. The analyses of the TBCs gave the following parameters for Port $1\left(\mathrm{v}=4.13 \times 10^{-6} \mathrm{~m} / \mathrm{s}\right)$; dispersivity (longitudinal) $\left[\alpha_{\mathrm{L}}\right]=0.06 \mathrm{~cm}$, dispersion coefficient $\mathrm{D}=1.6 \times 10^{-6} \mathrm{~m}^{2} / \mathrm{s}$, dispersivity (horizontal transverse) $\left[\alpha_{\mathrm{T}}\right]=0.006 \mathrm{~cm}$.

The analyses of the TBCs gave the following parameters for Port $2\left(\mathrm{v}=1.14 \times 10^{-5} \mathrm{~m} / \mathrm{s}\right)$; dispersivity (Longitudinal) $\left[\alpha_{\mathrm{L}}\right]=0.16 \mathrm{~cm}$, dispersion coefficient D $=6.9 \times 10^{-6} \mathrm{~m}^{2} / \mathrm{s}$, dispersivity (horizontal transverse) $\left[\alpha_{\mathrm{T}}\right]=0.016 \mathrm{~cm}$. These parameters would be used in the contaminant transport, advection-dispersion model for The analysis of dissolved contaminant fate and transport away from source areas. This is an important component in the evaluation of risk posed to down gradient receptors, of monitoring plan development and of remedial alternative selection. The properly characterized sand tank model is intended to serve as an economic and versatile tool for simulating and understanding field conditions of soil/ground water contamination for similar tropical aquifer materials.

\section{ACKNOWLEDGEMENT}

The authors would like to acknowledge the funding by the Federal University of Technology, Akure, Ondo State, Nigeria. The authors would also thank the University research grant URG/MAJOR/2006/16 and postgraduate students Fijabi, D. O and Chiwumba, O.C for their involvement in data collection.

\section{REFERENCES}

Adams, R. H.; Guzman-Osorio, F. J., (2008). Evaluation of land farming and chemico-biological stabilization for treatment of heavily contaminated sediments in a tropical environment. Int. J. Environ. Sci. Tech., 5 (1), 169-178 (10 pages).

Adams, R. H.; Guzman-Osorio, F. J.; Zavala Cruz, J., (2008). Water repellency in oil contaminated sandy and clayey soils. Int. J. Environ. Sci. Tech., 5 (4), 445-454 (10 pages).

BS 1377 (1990). Method of test for soil for civil engineering purpose. British Standard Institute, London.

Chrysikopoulos, C. V.; Lee, K. Y., (1998). Contaminant transport resulting from multicomponent nonaqueous phase liquid pool dissolution in three-dimensional subsurface formations. J. Contam. Hydrol., 31 (1-2), 1-21 (21 pages).

Cirpka, O. A.; Kitanidis, P. K., (2000). Characterization of mixing and dilution in heterogeneous aquifers by means of local temporal moments. Water Resour. Res., 36 (5), 12211236 (16 pages).

Cussler, E. L., (1984). Diffusion: Mass Transfer in Fluid Systems. Cambridge University Press, New York.

Das, P.; Pal, R.; Chowdhury, A., (2008). Influence of bioticabiotic factors on the degradation of novaluron in tropical soil. Int. J. Environ. Sci. Tech., 5 (3), $425-429$ (5 pages).

Das Braja, M., (1990). Principles of geotechnical engineering. PWS-KENT Publishing Company, Boston, Massachusetts, 7-98.

Dela Barre, B. K.; Harmon, T. C.; Chrysikopoulos, C. V., (2002). Measuring and modeling the dissolution of nonideally shaped dense nonaqueous phase liquid pools in saturated porous media. Water Resour. Res., 38 (8), 11331148 (16 pages).

Domenico, P. A.; Schwartz, F. W., (1990). Physical and chemical hydrogeology. John Wiley and Sons, New York, USA.

Freeze, R. A.; Cherry, J. A., (1979). Groundwater. PrenticeHall, New Jersey, USA.

Freyberg, D. L., (1986). A natural gradient experiment on solute transport in a sand aquifer: 2. Spatial moments and the advection and dispersion of nonreactive tracers. Water Resour. Res., 22 (13), 2031-2046 (16 pages).

Hassan, G.; Reneau, Jr., R. B.; Hagedorn, C.; Jantrania, A. R., (2008). Modeling effluent distribution and nitrate transport through an on-site wastewater system. J. Environ. Qual., 37 (5), 1937-1948 (12 pages).

Held, R. J.; Celia, M. A., (2001). Pore-scale modeling and upscaling of non-aqueous phase liquid mass transfer. Water Resour. Res., 37 (3), 539-549 (11 pages).

Iversen, B. V.; Keur, P. V.; Vosgerau, H., (2008). Hydrogeological relationships of sandy deposits: Modeling of two-dimensional unsaturated water and pesticide transport. J. Environ. Qual., 37 (5), 1909-1917 (9 pages).

Jebellie, S. J.; Madani, A.; Prasher, S. O., (2004). Computer simulation of fate and transport of metolachlor in a soil column study. Can. Water Resour. J., 29 (3), 159-170 (12 pages).

Jung, Y.; Coulidably, K. M.; Borden, R. C., (2006). Transport of edible oil emulsions in clayey sands: 3D sandbox results and model validation. J. Hydrol. Eng., 11 (3), 238 244 (7 pages).

Kasteel, R.; Vogel, H.; K. Roth, K., (2000). From local hydraulic properties to effective transport in soil. Eur. J. Soil Sci., 51 (1), 81-91 (11 pages).

Kim, J.; Park, Y.; Harmon, T. C., (2005). Real-Time parameter estimation for analyzing transport in porous media. Ground Water Monit. R., 25 (2), 78-86 (9 pages).

Kleineidam, S.; Rügner, H.; Grathwohl, P., (1999). Impact of grain scale heterogeneity on slow sorption kinetics. Environ. Toxicol. Chem., 18 (8), 1673-1678 (6 pages).

Lee, K. Y.; Chrysikopoulos, C. V., (1998). NAPL pool dissolution in stratified and anistropic porous formations. J. Environ. Eng., 124 (9), 851-862 (12 pages).

Leland, D. F.; Hillel, D., (1981). Scale effects on measurement of dispersivity in a shallow unconfined aquifer. Paper 
presented at Chapman Conference on Spatial Variability in Hydrologic Modeling. AGU. Fort Collins. CO., July 2123.

MacKay, D. M.; Cherry, J., (1989). Groundwater contamination: Limits of pump-and-treat remediation. Environ. Sci. Tech., 23 (6), 630-636 (7 pages).

Mackay, D. M.; Shiu, W. Y.; Maijanen, A.; Feenstra, S., (1991). Dissolution of non-aqueous phase liquids in groundwater. J. Contam. Hydrol., 8 (1), 23-42 (20 pages).

Meyer, B. R.; Bain, C. A. R.; DeJesus, A. S. M.; Stephenson, D., (1981). Radiotracer evaluation of groundwater dispersion in a multilayer aquifer. J. Hydrol., 50 (1-3), 259-271 (13 pages).

Mirbagheri, S. A.; Hashemi Monfared, S. A., (2009). Pesticide transport and transformation modeling in soil column and groundwater contamination prediction. Int. J. Environ. Sci. Tech., 6 (2), 233-242 (10 pages).

Ola, S. A. (1983). Geotechnical properties of some Nigerian lateriic soils. Tropical soils of Nigeria in engineering practice. in: Ola, S. A. (Ed.), 61-84.

Olaf A. C.; Olsson, A.; Ju, Q.; Rahman, A; Grathwohl, P., (2003). Determination of Transverse Dispersion Coefficients from Reactive Plume Lengths., Groundwater, 44 (2), 212-221 (10 pages).

Pignatello, J. J., (1989). Sorption dynamics of organic compounds in soils and sediments. in: Sawney, B. L.; Brown, K. (Eds.), Reactions and movement of organic chemicals in soils. Soil Science Society of America, Madison, Wisconsin, 45-81.

Plamer, C. M., (1992). Principles of contaminant hydrogeology. Lewis Publishers, Chelsea, Michigan, USA.

Ranjan, G.; Rao, A. S. R., (2000). Basic and applied soil mechanics. New age international (P) limited, publisher, $100-101$

Simpson, M. J.; Clement, T. P.; Gallop, T. A., (2003). Laboratory and numerical investigation of flow and transport near a seepage-face boundary. Ground water, 41 (5), 690-700 (10 pages).

Sudicky, E. A., (1986). A natural gradient tracer experiment on solute transport in a sand aquifer: Spatial variability of hydraulic conductivity and its role in the dispersion process. Water Resour. Res., 22 (13), 2069-2082 (14 pages).

Torres, L. G. B.; Climent, M.; Saquelares, J.; Bandala, E. R.; Urquiza, G.; Iturbe, R., (2007). Characterization and treatability of a contaminated soil from an oil exploration zone.Int. J. Environ. Sci. Tech., 4 (3), 311-322 (12 pages).

Ursino, N.; Gimmi, T., (2004). Combined effect of heterogeneity, anisotropy and saturation on steady state flow and transport: Structure recognition and numerical simulation. Water Resour. Res., 40 (1), WO1514.

Victor, S., (2008). Nigerians die annually from water diseasesWHO. THE PUNCH Newspaper, Wednesday, July 2, 9.

Walton C. W, (1991). Principle of Groundwater Engineering. Lewis Publishers. Michigan.

Wang, G.; Lu, Y.; Wang, T.; Zhang, X.; Han, J.; Luo, W.; Shi, Y.; Li, J.; Jiao, W., (2009). Factors influencing the spatial distribution of organochlorine pesticides in soils surrounding chemical industrial. parks. J. Environ. Qual., 38 (1), 180-187 (8 pages).

Wiedemeier, T. H.; Rifai, H. S.; Newell, C. J.; Wilson, J. T., (1999). Natural attenuation of fuels and chlorinated solvents in the subsurface. John Wiley and Sons Inc., New York.

Wildenschild, D.; Jensen, K. H.; Villholth, K.; Illangasekare, T. H., (1994). A laboratory analysis of the effect of macropores on solute transport. Ground Water, 32 (1), 381-389 (9 pages)

Zhang, Y.; Zhu, D.; Yu, H., (2008). Sorption of aromatic compounds to clay mineral and model humic substanceclay complex: effects of solute structure and exchangeable cation. J. Environ. Qual., 37 (3), 817-823 (7 pages).

\section{AUTHOR (S) BIOSKETCHES}

Ojuri, O., Ph.D., Lecturer, Department of Civil Engineering, Federal University of Technology, Akure, and researcher in geotechnical engineering at the Federal University of Technology, Akure, Ondo State, Nigeria. Email: ojurip@yahoo.com

Ola, S. A., Ph.D., Professor of geotechnical engineering, Department of Civil Engineering, Federal University of Technology, Akure, Ondo State, Nigeria. Email: samuelola41@yahoo.com

How to cite this article: (Harvard style)

Ojuri, O.; Ola, S. A., (2010). Estimation of contaminant transport parameters for a tropical sand in a sand tank model. Int. J. Environ. Sci. Tech., 7 (2), 385-394. 